\title{
Informal Risk Sharing in an Infinite-horizon Experiment
}

\author{
Gary Charness \\ University of California, Santa Barbara \\ Garance Genicot
}

Georgetown University

January, 2007

\begin{abstract}
This paper presents the first laboratory study of risk-sharing without commitment. Our experiment captures the main features of a simple model of voluntary insurance between two agents. In the model, two individuals interact over a potential infinite horizon and suffer random income shocks. Risk-averse individuals have incentives to smooth consumption by making transfers to each other. These transfers being voluntary, only self-enforcing risk-sharing arrangements are possible: transfers can never be so large as to tempt individuals to renege on them. This constraint, when binding, has strong implications for the shape of the constrained optimal risk-sharing arrangement.

In our experiment, participants are matched in pairs. Each period, one of them, randomly drawn, receives a given amount $h$ in addition to its regular income. After observing both incomes, each person in a pair chooses a non-negative transfer to make to the other person. Two features of the experimental design are crucial. First, it is common information that all pairs will be dissolved at the end of each period with a given probability. Participants are informed when this occurs and randomly re-matched. This replicates the effect of infinite-horizon and discounting in the model. Second, at the end of the experiment, a unique period is randomly drawn to count for cash payment. This feature is essential to isolate for the utility outcome of each period.

We find evidence generally consistent with risk sharing, with higher transfers coming from individuals who received $h$ in the period. Moreover, in support of the theory, transfers are much higher with a higher continuation probability and they also are highly correlated with the individual's degree of risk aversion. However, while the model predicts an increase in transfers with ex ante inequality, we observe the opposite effect. This may reflect considerations of identity or group membership.
\end{abstract}

JEL Classification Numbers: O17, A49, C91, C92, D31, D81.

Key Words: experiment, gift exchange, informal insurance, risk sharing.

We are grateful to the California Social Science Experimental Laboratory at UCLA, particularly to Patricia Wong for arranging the logistics and to Raj Advani for expert programming. We also thank Arik Levinson and Roger Lagunoff for their helpful suggestions, as well as seminar participants at Princeton University, the World Bank DECRG, Boston University, Georgetown University, George Washington University, the University of Virginia, the NEUDC at Yale University and the SED conference in Florence. Charness thanks the UCSB Academic Senate and the Russell Sage Foundation for support. Please address all correspondence to charness@econ.ucsb.edu and gg58@georgetown.edu. 


\section{INTRODUCTION}

Risk is a pervasive fact of life for most people, especially in developing countries. Individuals have often been shown to respond to the large fluctuations in their income by engaging in informal risk sharing by providing each other with help in the form of loans, gifts and transfers in time of need. There is considerable empirical evidence that risk sharing provides significant, albeit limited, insurance in village communities. ${ }^{1}$ The most important limitation appears to arise from the lack of enforceability of these risk-sharing agreements. The fact that these agreements must be designed to elicit voluntary participation often seriously limits the extent of insurance they can provide. A growing theoretical literature provides a characterization of the optimal self-enforcing risk-sharing agreement and some of its consequences. ${ }^{2}$

This paper is, to the best of our knowledge, the first laboratory study of risk sharing without commitment. We chose a very simple model in which one of two paired agents, selected at random in each period, receives an amount of money $h$ in addition to his or her fixed income.

In what follows, we describe an experiment in which we replicated the setting of this model of risk sharing without commitment and tested specific features of risk sharing, such as the various effects of risk aversion, the time horizon, ex ante inequality, and beliefs.

Our experiment captures the main features of the model. Individuals are matched in pairs; matches have uncertain duration, with all pairs dissolved at the end of each period with a ten or twenty percent chance, depending on the treatment. In every period, each person observes the interim income and may then make a transfer to the other person. Participants all face the

\footnotetext{
${ }^{1}$ See for example Deaton (1992), Townsend (1994), Udry (1994), Jalan and Ravallion (1999), Ligon, Thomas and Worrall (2002), Grimard (1997), Gertler and Gruber (1997), and Foster and Rosenzweig (2002).

${ }^{2}$ Among others, see Kimball (1988), Coate and Ravallion (1993), Kocherlakota (1996), Kletzer and Wright (2000), Ligon, Thomas and Worrall (2002), Genicot and Ray (2003), and Genicot (2003).
} 
same variance in their income, but do not necessarily have the same mean income. At the end of the experiment, one period is randomly drawn to count for cash payment.

We find evidence of significant but limited risk sharing in the experimental data. Within pairs, transfers are essentially flowing from individuals who received $h$ to the other. To be sure, the fact that experimental transfers are providing insurance does not per se establish that the strategic considerations highlighted in the model are at play, since these transfers can also reflect some form of altruism or social preference. However, we find evidence in the experimental data for some specific implications of our model.

First, we find that average transfers double when there is a $90 \%$ likelihood that a match will continue into the next round compared to when there is only an $80 \%$ likelihood of continuation. Second, we find a positive correlation between the individuals' degree of risk aversion and the extent of risk-sharing in which they engage. Unless altruism is correlated with risk aversion, social-preference models would not predict this correlation. In fact, the degree of (measured) risk aversion helps predict transfers, in the expected direction. Finally, reciprocal behavior is shown to be an important factor: the higher the first transfer made by an individual's partner within a match, the higher the individual's transfer made upon receiving a good shock. Without denying that other considerations could simultaneously be in effect, this evidence suggests that strategic considerations are important in explaining the data.

Since we examine matches where the individuals have the same fixed income as well as matches featuring unequal fixed payoffs, we test for the effect of ex ante inequality on risk sharing. Genicot (2007) studies risk sharing between two agents who face the same income fluctuations and preferences but differ in their fixed income; in theory, inequality should increase risk sharing for a large range of preferences. We instead find that inequality actually decreases 
risk sharing, and we discuss explanations based on both ease of coordination and one's identity (as in Akerlof and Kranton 2000) or salient group membership (Charness, Rigotti, and Rustichini 2003).

Finally, we examine whether we see systematically different risk sharing for males and females. Economists and policy-makers have observed gender differences in a number of different economic domains, with important implications for policy; see Croson and Gneezy (2004) for a review. Controlling for females' greater risk aversion, we find that males transfer significantly more than females do. While this result seems surprising, it is consistent with evidence that women's consumption in developing countries fluctuates more than men's (see for instance Dercon and Krishnan 2000, and Dubois and Ligon 2004 for young women).

The remainder of this paper is organized as follows: Section 2 reviews the related literature, and we present the basic model of risk sharing without commitment and describes some important implications in Section 3. We describe the experimental design in Section 4, and the main results of the experiment are presented in Section 5. Section 6 offers a discussion of some implications of the paper, and Section 7 concludes.

\section{RELATED EXPERIMENTAL LITERATURE}

Previous experimental work on risk sharing is rather limited. In a field experiment in Zimbabwe, Barr and Genicot (2007) conducted one-shot risk-sharing games among villagers who had been observed to share risk with each other. Prior to choosing a lottery in which they wish to participate, individuals are explicitly provided with the some risk-sharing option either with commitment to an equal split or, in other village, with the possibility of keeping one's return without this being directly disclosed to others (though they can infer some information 
from the payoff they receive, especially in small groups). They find more participation in risksharing groups, larger groups and more risk taking in the first case. Looking at the possibility of public withdrawals from risk sharing groups, they conclude that both intrinsic and extrinsic motivations are important.

Field experiments are important and have the advantage of using truly representative participants. However, they suffer from some limitations. Experiments in the field are typically conducted without anonymity; since participants are engaged in many other interactions than the experiment (and so motivations outside of these models are likely to enter into the picture), the interpretation of the observed field behavior in terms of these models may not be clear. In this sense, laboratory experiments offer certain advantages with respect to experimental control, and they also enable the researcher to systematically vary particular features of the environment that are relevant or even crucial to theoretical models. In this way, theory can be brought into closer alignment with behavior. Of course, it is very important that laboratory experiments are externally valid, successfully distilling the essential elements of the field environment.

Perhaps the most closely-related laboratory experiment to ours is the Selten and Ockenfels (1998) "Solidarity Game" since our experiment is effectively a solidarity game if the match continuation probability is zero. In their game, each of three players has an ex ante independent $2 / 3$ chance of winning $10 \mathrm{DM}$ and a $1 / 3$ chance of receiving nothing. Before learning the outcome, each player decides on an amount that she commits to give to one loser or to each of two losers, if she actually won the $10 \mathrm{DM}$ and there are one or two losers. The great majority of subjects were willing to make some conditional gifts. ${ }^{3}$ They distinguish five

\footnotetext{
${ }^{3}$ However, the design of their experiment and the fact that transfers are elicited only from winners may be driving some of their results.
} 
behavioral types, with the most common type (36\%) giving the same total amount to one loser and to two losers. This behavior is not readily explained by altruistic utility maximization.

Bone et al. (2004) report an experiment designed to test whether pairs of individuals are able to exploit efficiency gains in the sharing of a risky financial prospect (taking advantage of their difference in risk aversion, with commitment). Their results indicate that fairness is not a significant consideration, but rather that having to choose between prospects diverts partners from allocating the chosen prospect efficiently. The pattern of agreements suggests that, where allocation is the sole issue, partners largely favor ex ante efficiency over ex post equality. From the transcripts there is little indication that ex post fairness is a significant consideration.

Our experiment is also related to the literature on cooperation in "infinitely-repeated games", where there is a known likelihood of the experimental session terminating after each round, possibly after some initial rounds played with certainty. There have been many experimental studies in which a game is repeated finitely many times, and it is well-known that behavior differs in one-shot games and repeated games. Yet there is a tendency for the finite version to unravel when the known last period approaches, coloring the behavior along the way.

Axelrod (1980) was the first to use a stochastic ending in an experimental tournament on the prisoner's dilemma. Roth and Murnighan (1978) and Murnighan and Roth (1983) examine the effects on behavior of changing the termination probability, finding some differences between a low probability of continuation and moderate or high probabilities of continuation, but little difference across moderate and high continuation probabilities. Dal Bó (2005) performs a careful study of infinitely-repeated games, with control sessions with finitely-repeated games of the same length as that expected in the infinitely-repeated version. The main findings are that 
behavior varies considerably across different continuation probabilities and that the "shadow of the future" has an effect, as there is more cooperation with 'infinite repetition'.

Nevertheless, while other studies have explored behavior in an infinite-horizon context, we are unaware of any previous experiment that is explicitly devised to study risk sharing without commitment.

\section{A Model of Risk Sharing Without CoMmitMent}

A standard model of risk sharing without commitment goes as follows: Time is discrete and the number of period is infinite. In each period $t$, two agents, indexed by $i \in\{1,2\}$, receive an income $y_{i}$ and one of them (chosen at random) also receives a fixed monetary gain $h$. They each have a probability $1 / 2$ of receiving $h$ but the aggregate income is constant at $Y=y_{1}+y_{2}+h$ in each period. The following table summarizes the income distribution of the two agents:

\begin{tabular}{|c|c|c|}
\cline { 2 - 3 } \multicolumn{1}{c|}{} & State $1(p=1 / 2)$ & State $2(p=1 / 2)$ \\
\hline Agent 1 & $y_{1}+h$ & $y_{1}$ \\
\hline Agent 2 & $y_{2}$ & $y_{2}+h$ \\
\hline
\end{tabular}

In line with standard practice, let us assume that all agents have additively time-separable Von Neumann-Morgenstern utility functions defined over consumption, such that the expected lifetime utility of an agent is given by

$$
E \sum_{t=0}^{\infty} \beta_{t} u_{i}\left(c_{t}^{i}\right) \forall i \in\{1,2\}
$$

with $u_{i}^{\prime}>0, u_{i}^{\prime},<0, \lim _{c \rightarrow 0} u_{i}^{\prime}(c)=-\infty$, and where $\beta_{t} \in(0,1)$ is the discount factor.

Since individuals are risk-averse and aggregate income is constant, optimality would require transfers between the agents that keep each individual's consumption constant across time and

\footnotetext{
${ }^{4}$ There are other studies in experimental economics using an explicit stochastic ending, such as Cason (1995) and Charness and Garoupa (2000).
} 
state of nature. The exact consumption levels $c_{1}{ }^{*}$ and $c_{2}{ }^{*}$ depend on the welfare weights used, but must sum to the aggregate income $Y$ and satisfy the voluntary participation constraint.

As motivated and discussed in the Introduction, we focus on the theme that insurance arrangements must be self-enforcing, and that this requirement constrains the form of such arrangements. The enforcement constraint refers to the possibility that at some date, an individual who is called upon to make a transfer refuses to make this transfer. To be selfenforcing, a risk-sharing agreement must be such that the expected net benefits from participating in the agreement is at any point in time larger than the one time gain from defection. The literature on risk sharing concentrates on the constrained optimal or 'second-best' self-enforcing schemes. It follows that the constraint is modeled by supposing that a deviating individual is excluded and must then bear stochastic fluctuations alone. ${ }^{5}$ A risk-sharing agreement consists in a profile of transfers for all date $t$ and realized state $s \in\{1,2\}$ that result in a stream of consumptions $\left\{c_{t}^{i}(s)\right\}_{\forall i, t}$. These consumptions implies an expected continuation utility $v_{t+1}^{i} \equiv E_{t} \sum_{j=1}^{\infty} \beta_{j, t} u_{i}\left(c_{t+j}^{i}\right)$ at any date $t$ for individual $i \in\{1,2\}$, where $\beta_{j, t}$ is the relative weight on the utility from consumption at time $t+j$ compared with consumption at time $t$ (the discount on future consumption). In contrast, an individual $\mathrm{i}$ who deviates at time $t$ would consume his or her income $z_{t}^{i}$ (the sum of $y_{i}$ and $h$, if received this period) from time $t$ onwards with a continuation utility $v_{t+1}^{i, a u t} \equiv E_{t} \sum_{j=1}^{\infty} \beta_{j, t} u_{i}\left(z_{t+j}^{i}\right)$. Hence, a risk sharing agreement selfenforcing if, for every period $t$ and individual $i \in\{1,2\}$,

$$
u_{i}\left(c_{t}^{i}\right)+v_{t+1}^{i} \geq u_{i}\left(z_{t}^{i}\right)+v_{t+1}^{i, a u t} .
$$

\footnotetext{
5 Equivalently, the deviator could be given the same continuation utility as in autarchy.
} 
If the power of such punishment is limited, then perfect insurance may not be possible. However, even when full risk sharing is not possible, individuals may be able to design a risksharing agreement by limiting transfers in states for which the enforcement constraint is binding (see Coate and Ravallion, 1993 and Kocherlakota, 1996, among others).

In fact, with this simple distribution, the constrained optimal agreement $\left\{c_{t}^{i *}\right\}_{\forall t}$ and its associated continuation utility $v_{t+1}^{* i}$ at any time $t$ are easy to characterize. Individuals make positive transfers to each other in the state in which they receive a good income shock $h$, so that an individual's incentive constraint would only bind when he has received $h$. If an individual $i$ 's incentive constraint bind at time $t$, her consumption is determined by the binding constraint

$$
u_{i}\left(c_{t}^{i *}\right)+v_{t+1}^{* i}=u_{i}\left(y_{i}+h\right)+v_{t+1}^{i, a u t}
$$

and $c_{t}^{j *}=Y-c_{t}^{i} *$ for $j \neq i$; otherwise the individuals' consumptions at time $t$ are just kept at the same level as the previous period.

For the simple exponential discounting, where $\beta_{j, t}=\delta^{j}$ for all $t$ and $j$, the constrained optimal agreement is characterized by two values, $t_{1} *$, the transfer made by 1 to 2 when 1 received $h$ and, $t_{2}{ }^{*}$, the transfer made by 2 to 1 when 2 received $h .^{6}$ These transfers are such that the incentive constraints (2) hold with equality for both agents, that is $t^{*}=\left(t_{1}^{*}, t_{2}^{*}\right)$ is defined by:

\footnotetext{
${ }^{6}$ This is true for all constrained optimal arrangement, irrespective of the initial bargaining power of the agent. The constrained-optimal scheme may specify a slightly smaller transfer than $t_{1} *$ to an agent as long as only she has received $h$ in order to give to this agent a larger share of the surplus. However, as soon as the state in which the other agent receives $h$ occurs then the constrained optimal agreement is stationary and consists of $t^{*}$. In this special case, the stationary agreement studied in Coate and Ravallion (1993) is therefore optimal.
} 


$$
\begin{aligned}
& \left(1-\frac{\delta}{2}\right) u_{1}\left(y_{1}+h-t_{1}^{*}\right)+\frac{\delta}{2} u_{1}\left(y_{1}+t_{2}^{*}\right)=\left(1-\frac{\delta}{2}\right) u_{1}\left(y_{1}+h\right)+\frac{\delta}{2} u_{1}\left(y_{1}\right) \\
& \left(1-\frac{\delta}{2}\right) u_{2}\left(y_{2}+h-t_{2}^{*}\right)+\frac{\delta}{2} u_{2}\left(y_{2}+t_{1}^{*}\right)=\left(1-\frac{\delta}{2}\right) u_{2}\left(y_{2}+h\right)+\frac{\delta}{2} u_{2}\left(y_{2}\right) .
\end{aligned}
$$

A first implication of this model is that, when full insurance is not achieved, a higher discount factor $\delta$ increases the weight put on the long-term gain from insurance relative to the short-term gain from deviating. It is easy to check that higher values of $\delta$ would relax the constraints in (4). When constrained, a higher $\delta$ raises the transfers that individuals are able to make to each other and so the insurance that they can provide for each other. There are threshold values $\underline{\delta}$ and $\bar{\delta}$, with $0<\underline{\delta}<\bar{\delta}<1$, such that for values of $\delta$ smaller or equal to $\underline{\delta}$ no risk sharing is possible, for $\delta \in(\underline{\delta}, \bar{\delta})$ there is some constrained insurance, and for values of $\delta$ greater than or equal to $\bar{\delta}$, first-best risk sharing can be achieved (see Thomas and Worrall 1994, Kocherlakota 1996 and Ligon, Thomas and Worrall 2002).

A second implication of this model is that an overall increase in the risk aversion exhibited by the agents increases $t^{*}$ and the level of risk sharing that individuals can achieve, by increasing the long term gain from insurance. For instance, if individuals have utility $\mathrm{u}_{i}(\mathrm{c})=\frac{1}{1-\rho_{i}} \mathrm{c}^{1-\rho_{i}}$, where $\rho_{i}$ is the Arrow-Pratt coefficient of relative risk aversion, then an increase $\rho_{i}$ relaxes $i$ 's incentive constraint (4), thereby improving the insurance possibilities (see the proof in Appendix).

Finally, what is the effect of inequality? Let's consider different values of $y_{1}$ and $y_{2}$ keeping the aggregate income $Y$ constant. Clearly, if $y_{1}=y_{2}$ both individuals are ex ante identical. Now, increasing $y_{1}$ and decreasing $y_{2}$ to keep $Y$ unchanged would make 1 relatively wealthier than 2, while keeping the variance of their income constant. To be sure, the set of 
Pareto optimal allocations is unaffected since the aggregate income is the same. However, the division of wealth affects the autarchic utility and thereby does affect the set of self-enforcing allocations. Genicot (2007) shows that for a large range of utility functions such spreadpreserving inequality between the two agents increases the likelihood of first-best risk sharing and increases the transfers that agents make within the constrained optimal agreement. ${ }^{7}$ This is because a spread-preserving increase in inequality relaxes the constraint of the poorer agent relatively more than it worsens the constraint of the richer agent.

Before we proceed to the description of our experiment, we wish to mention two caveats. First, this game suffers from the familiar problem of multiplicity of equilibria in infinitelyrepeated games. For instance, neither individual making any transfer is always an equilibrium of the game. As it is usual practice in the theoretical and the empirical literature, we focus on the constrained optimal arrangements, the arrangements that provide the most risk-sharing given the self-enforcing. Using this refinement what is striking is that when full insurance is not possible, as soon as both agents have once received $\mathrm{h}$, all constrained optimal arrangements -- irrespective of the initial bargaining weight of the agents -- are fully characterized by the two transfers $t^{*}$ in (4). Second, the assumption of perfect negative correlation for this shock is of course an extreme assumption; in real life, individuals face a variety of shocks, some of which are correlated with the shocks of other individuals; it is well known that the more correlated the income, the less risk sharing in which people can engage. As a next step in the research agenda, it would be interesting to consider idiosyncratic shocks, however the constrained optimal arrangement is then considerably more complex as it is non-stationary. ${ }^{8}$ Hence, we believe that constant aggregate

\footnotetext{
${ }^{7}$ See http://www.georgetown.edu/faculty/gg58/IIdraft.pdf.

${ }^{8}$ For example, we could consider an income process in which both individuals can receive $h$ with a probability $\mathrm{p}$, but without any correlation between their draws. In this case, the constrained optimal arrangement converges to a
} 
income is a good first step, for the purpose of generating simple theoretical predictions and a relatively transparent setting.

\section{EXPERIMENTAL DESIGN}

The challenge for our experimental design was to create an environment in which the behavior of our experimental subjects is interpretable in terms of the infinite-horizon model of risk sharing without commitment described in the previous section. To this end, we have participants matched in pairs. Each period, one of them, randomly drawn, receives a given amount $h$ in addition to its regular income. After observing both incomes, each person in a pair chooses a non-negative transfer to make to the other person. We first highlight some key features of our experimental design and then describe the detail of the implementation.

\section{Design Considerations}

The challenge for our experimental design was to create an environment in which the behavior of anonymous students playing a (necessarily) finite game with limited payoffs is interpretable in terms of a well-specified infinite-horizon model of risk sharing with commitment. Models of this nature are typically intended to reflect a field environment where individuals living in the same community experience large stochastic fluctuations in individual income, make voluntary transfers to each other to smooth consumption and see no clear termination to their repeated interaction.

We wished to have a relatively simple and transparent experimental environment. However, we refrained from using the terms "risk sharing" or "insurance" during the experiment, in order to avoid guiding the participants' behavior. As we wished to test for risk-sharing

non-stationary transfer scheme in which the individual supposed to make a transfer when they have the same income depends on the history of transfers. 
behavior without explicit agreements, no communication was permitted and thus all potential risk sharing was tacit. ${ }^{9}$ These factors make risk sharing more difficult to achieve; on the other hand, this is balanced against the assumption of constant aggregate income for each pair, which is an easier environment to comprehend, but may serve as a focal point and thus facilitate sharing.

A key feature of our experiment is that pairs of agents are matched for an uncertain number of periods. It is common information that all matches end with a given probability at the end of each period. This captures the assumption of infinite-horizon with discounting of the model, as there being only a limited probability of a future period gives this future period the same weight in one's utility function as with discounting.

Another important feature of our design is that we paid participants for only one period, drawn at random at the end of the experiment, from the numerous periods (typically 60 to 80 ) played over many matches. This is crucial. If every round counted towards her payoff, an individual would care about the distribution of the sum of income net of transfers over all rounds instead of the income net of transfers earned in each round. ${ }^{10}$ This would not only substantially reduce the variance in the subject's payoff in the absence of transfer, thereby reducing their incentive to share risk, but knowing the accumulated income to date would also affect the subject's behavior. In contrast, our procedure gives equal probability to any realized round within a match to be the "payoff round," so that individuals with expected utility would face

\footnotetext{
${ }^{9}$ We also avoided using a simple alternation scheme, where each person in a pair would receive $h$ with certainty every other period.

${ }^{10}$ If every round counted for her payoff, individual i would maximize $u_{i}\left(E \sum_{=0}^{\infty} c_{t}^{i}\right)$ where $c_{t}^{i}$ is individual $i$ 's income (fixed plus variable) plus the net transfer received in round t. In contrast in our experiment, her expected utility is $E_{c, t^{*}} u_{i}\left(c_{t^{*}}^{i}\right)$, where $t^{*}$ is the round selected. See more details in the Appendix.
} 
incentives constraints similar to (4) in each match. The Appendix explains in details how our procedure achieves this result.

We expect one's risk attitude to be important in determining one's transfer. Hence, prior to the main experiment, we asked subjects to participate in a lottery to elicit a measure of their risk aversion. Using the subjects' own attitude towards risk suffers from the usual criticism that, given the small stakes, risk aversion cannot be an important factor in the decision (see Rabin 2002). An alternative approach would be to induce risk neutrality (the binary lottery procedure). Although this method should in theory enable the experimenter to predetermine any functional form for subjects' utility functions, experimental evidences show that in practice subjects' own preferences affect their choices making it very difficult to interpret the results (Camerer and Ho, 1994, Selten et al., 1999). As a result, we chose measure risk attitudes and directly control for them.

An additional concern might be that monetary rewards are relatively small compared to the field environment. However, our financial payoffs are quite in line with normal experimental rewards, and the size of the stochastic payoff from the chosen period was rather large in experimental terms (nearly $\$ 12$ ). Thus, the degree of payoff risk from not engaging in risk sharing was not inconsequential. Nevertheless, this risk is clearly not as severe as it can be in the field.

Finally, we needed to pay attention to the time duration of the experiment. If, for example, participants know that an experiment is scheduled to last for one hour, and 55 minutes have already passed, they might expect the experiment to end very soon and we might observe serious unraveling. To minimize this concern, we calibrated sessions to last for only 60 minutes while advertised sessions of 90 minutes in duration. We retained a good degree of control over 
the duration of sessions: Participants played in up to 7-10 matches in a session, but we were prepared to reduce the number of matches played if necessary by announcing at the appropriate time that the next match would be the last one. The participants were told this and also were told that we were aiming to end the experiment in an hour, but that we had nevertheless reserved 90 minutes of their time. In this manner, we kept the time horizon at a considerable distance.

\section{Implementation}

All experiments were conducted at the CASSEL Laboratory in UCLA. We had six sessions, with an even number of participants ranging from 12 to 18 in a session (depending on show-ups). Participants earned an average of about $\$ 17$ for about an hour of their time. The procedures that we followed are described below and the complete experimental instructions for the $\delta=.9$ treatment are shown in Appendix A.

Prior to the main experiment, we first asked people to complete an investment question. For this exercise, each person was provisionally endowed with 100 units and could invest any portion of this amount in a risky asset that had a 50\% chance of success. The investment paid 2.5 times the amount invested if successful, but nothing if unsuccessful; the decision-maker retained all units not invested. All of this was verbally explained in detail to the participants. This technique was adapted from the design in Gneezy and Potters (1997) and is an easy-tounderstand mechanism for measuring risk aversion. Using a 50\% probability of success also avoids the problem of subjective over-weighting of low-probability events.

We told the participants that we would later choose two people at random in each session for actual payoff implementation; we did so at the end of the session. We then flipped a coin to determine success or failure for these investors, and added this payment to the amount earned in the main experiment. For this exercise, each unit was worth $\$ 0.10$ for the investors who were 
selected. This investment question provides us with a measure of risk aversion for each individual; clearly, the higher the investment the less risk averse is the individual.

The body of the session then consisted of a number of matches. For the duration of each match, every participant was paired with one other person. Each match was comprised of an uncertain number of periods, determined as follows: After each round, the computer determined (for all current matches) whether another round would follow. In three of our sessions (Treatment 1), the continuation probability was $80 \%$, and in the other three sessions (Treatment 2), the continuation probability was $90 \%$. In the first case, the expected number of subsequent rounds in a match (at any point in time after the first round) was four, and in the latter case, the expected number of subsequent periods was nine. The participants in the corresponding sessions were informed of the relevant mathematical fact.

The continuation probability is designed to play the same role in the decision process of the experimental subjects as the discount factor in Section 2. Ex ante, we expected each match to last five rounds in Treatment 1 and ten rounds in Treatment 2. We ended all matches at the same time, and all participants were randomly re-matched within their category for the next match. We had ten matches in each $80 \%$ session and seven matches in each $90 \%$ session. $^{11}$

In each round, each person received income, which was comprised of a fixed portion and an amount that was added to the fixed income for that round for one of the people in each match. The person receiving this extra amount was randomly chosen in each pair for every round of the match. The fixed portions did not vary during the match, but did change from match to match. Over time, matches alternated between having both fixed portions be 70 units (equality) and having the fixed portions be 20 and 120 (inequality). In all cases, the amount randomly assigned

\footnotetext{
${ }^{11}$ While random re-matching means that a participant might be anonymously matched with another participant more than once, the resulting possible repeated-play issue was not really salient, given the number of matches played and the number of participants visibly present in a session.
} 
and added was 200 units. This income distribution corresponds to the two-state distribution with constant aggregate income described in Section 2. Participants received $\$ 1$ for every 17 experimental payoff units in these matches, as is clearly indicated in the instructions.

In the beginning of a new match, each participant is informed that he or she is matched with a new partner, and learns his or her fixed income as well as the fixed income of the other person in the match. In the beginning of each round within a match, both individuals see which one of them received the extra 200 in this round. Each participant then designated a nonnegative amount (no greater than the total income received in the period) to transfer to the other person; these amounts were then transferred. We allowed individuals to make transfers whether or not they had received the 200 units as we did not want to bias the experiment in favor of risk sharing, and as we did not want the subjects to infer the main topic of the experiment. Participants saw a history of the income and transfers for each previous round in that match, and could also review their previous matches.

We also asked participants individuals who did not receive $h$ in the beginning of the first and fourth matches for their expectation of the transfer to be made by the other person. At the end of the session, participants answered questions concerning their gender and major before receiving their payoff.

\section{Main Results}

We first present some summary statistics about our data. We then address the following questions:

Question 1: Does a higher continuation probability increase the amount of risk sharing?

Question 2: Does a higher degree of risk aversion increase the transfer made?

Question 3: What is the effect of ex ante inequality on risk sharing? 
Question 4: How do past transfers from the other affect risk sharing?

Question 5: Are transfers sensitive to whether expectations are met?

Question 6: Are there differences in transfer choices for men and women?

The first three questions are directly related to the theoretical predictions of Section 3. In this model, there is no uncertainty so that deviations from the risk-sharing arrangement would be punished by the strongest punishment (autarchic payoff) but do never occur in equilibrium. Now, in the experimental setting there is likely to be some uncertainty due to the coordination process. If we added a little bit of noise to the model such as a small probability of making a mistake in the transfer, the punishment would be smaller and would occur in equilibrium. Agents respond to smaller transfers than expected by reducing their transfers, at least in the short term. Learning about the preference characteristics of one's partner would only accentuate this effect. $^{12}$ Hence, in response to Questions 4 and 5, we predict that transfers will respond positively to past transfers from other and in particular that transfers will decrease when expectations are not met.

Data summary. The experiment generated data on 4,112 transfers. Table 1 and Table 2 describe the aggregated data, while the details of the session and the session-level data are presented in Appendix B.

First, we observe from Table 1 that a substantial amount of transfers takes place, and that average transfers when ahead (upon receiving $h$ ) are much larger than average transfers when behind; this effectively provides insurance to individuals. A simple binomial test (Siegel and Castellan, 1988) on individual data finds this to be very significant $(Z=7.98, p=0.000) .{ }^{13} \mathrm{~A}$

\footnotetext{
${ }^{12}$ Developing a full theoretical model of risk-sharing without commitment with learning is beyond the goal of this paper.

${ }^{13}$ Throughout the paper, we round $p$-values to three decimal places.
} 
more conservative test considers each session to be only one observation; since the transfers are higher in each of the six sessions when the chooser is ahead (see Appendix B), the difference is statistically significant on this basis ( $p=0.016$, one-tailed test). It is clear that people are not just randomly and arbitrarily transferring money, but are instead sensitive to which matched person receives $h$ in the round.

Table 1: Transfer made when receiving $h$ or not, by Treatment

\begin{tabular}{|c|c|c|}
\hline Treatment $1(\delta=.8)$ & Received $h$ & Did not receive $h$ \\
\hline Mean transfer (all) & 23.71 & 6.18 \\
\hline Proportion of zero transfers & $34.8 \%$ & $56.6 \%$ \\
\hline \multicolumn{3}{|l|}{ Treatment $2(\delta=.9)$} \\
\hline Mean transfer (all) & 49.49 & 11.73 \\
\hline Proportion of zero transfers & $23.9 \%$ & $38.6 \%$ \\
\hline
\end{tabular}

Table 1 shows that with a continuation probability of $80 \%$ (Treatment 1 ), we see an average transfer of about 23.71 upon receiving $h$ and, with a continuation probability of $90 \%$ (Treatment 2), the average transfer when ahead rises to 49.49. People who do not receive $h$ regularly make positive but very small transfers: the median transfer is 0 in Treatment 1 and 3 in Treatment 2. Note that transfers when not receiving $h$ are not predicted by the risk-sharing model, or indeed by any of the social-preferences models. We return to this and discuss possible explanations in Section 5.

Thus far we have seen that there are significant transfers made, and that these appear to be dependent on both the continuation probability and whether the chooser has received $h$ or not. Table 2 shows average transfers after receiving $h$ (the standard deviation is in parentheses). In every case, transfers are highest when individuals have the same fixed income and lowest for people with a fixed income of 20; it is a bit surprising that transfers are a bit higher with a fixed 
income of 70 than with a fixed income of 120 , particularly since all of the distributional models of social utility predict the opposite. Once again, we expect higher transfers with a higher $\delta$, holding the fixed income constant and we observe this for each level of fixed income.

Table 2: Average transfer made when receiving $h$

Fixed Income $y_{i}$

\begin{tabular}{|c|c|c|c|c|}
\cline { 2 - 5 } \multicolumn{1}{c|}{} & 20 & 70 & 120 & Overall \\
\hline $\begin{array}{c}\text { Treatment 1 } \\
(\delta=0.8)\end{array}$ & $\begin{array}{c}16.31 \\
(20.90)\end{array}$ & $\begin{array}{c}28.19 \\
(32.52)\end{array}$ & $\begin{array}{c}25.80 \\
(40.27)\end{array}$ & $\begin{array}{c}23.71 \\
(32.42)\end{array}$ \\
\hline $\begin{array}{c}\text { Treatment 2 } \\
(\delta=0.9)\end{array}$ & $\begin{array}{c}32.07 \\
(33.84)\end{array}$ & $\begin{array}{c}55.45 \\
(49.81)\end{array}$ & $\begin{array}{c}54.61 \\
(61.19)\end{array}$ & $\begin{array}{c}49.49 \\
(50.48)\end{array}$ \\
\hline Aggregated & $\begin{array}{c}25.55 \\
(30.18)\end{array}$ & $\begin{array}{c}47.50 \\
(47.10)\end{array}$ & $\begin{array}{c}42.94 \\
(55.50)\end{array}$ & $\begin{array}{c}40.36 \\
(46.58)\end{array}$ \\
\hline
\end{tabular}

The aggregation in these tables ignores the substantial heterogeneity present in the population, indicated by the large standard deviation in Table 1. Figure 1 shows the distribution of the average transfer made after receiving $h$ by each individual in the two treatments.

\section{Figure 1 - Distribution of Average Transfers, with \\ $\boldsymbol{h}$}

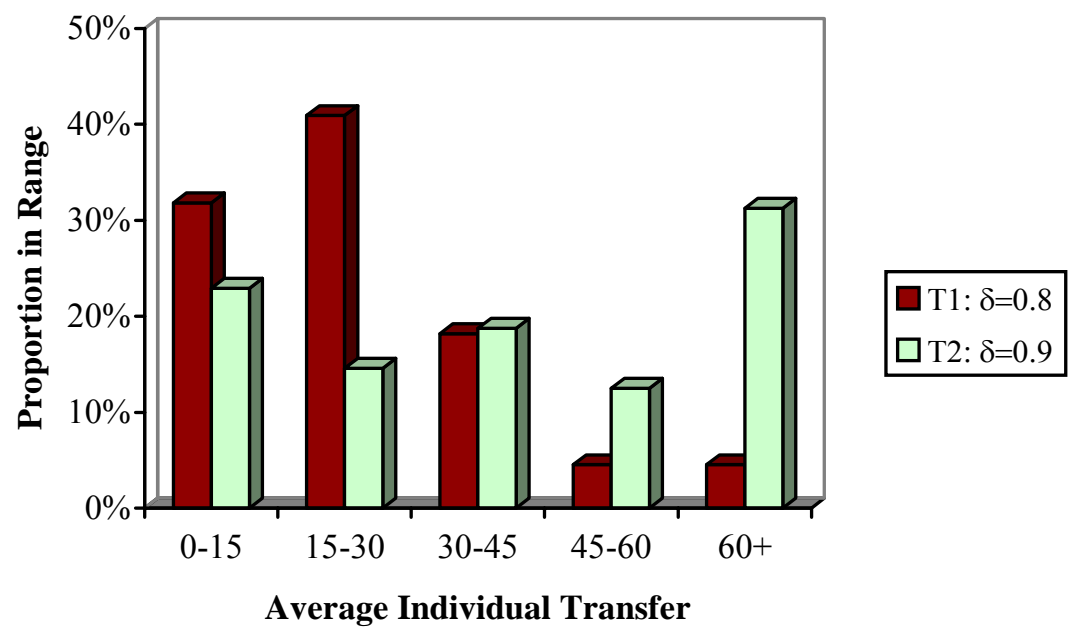


We see differences in these distributions across treatment. For example, while $31.2 \%$ of participants made average transfers greater than 60 after receiving $h$ in Treatment 2, only $4.5 \%$ did so in Treatment 1.

We now proceed to address the questions listed at the beginning of this section and to study the determinants of the transfers that individuals make. In our analysis, we supplement non-parametric statistical analysis with regression analysis. Given the censored nature of the transfers, we use random-effects Tobit regressions to account for unobserved individual characteristics and multiple observations for each participant. Table 3 presents the results of three different specifications of independent variables on all transfers made. Table 4 and Table 5 present the same regressions separately for transfers made by people who received $h$ in the current round and by people who did not receive $h .^{14}$

[Tables 3, 4 and 5 here]

Question 1: Continuation probability. One important prediction of the risk-sharing model is that we should see higher transfers when the expected time horizon is more distant. Tables 1 and 2 show that the average transfer is approximately double when the continuation probability is $90 \%$ instead of $80 \%$. Even if we conservatively consider each session to be only one independent observation, the Wilcoxon-Mann-Whitney ranksum test (Siegel and Castellan, 1988) finds that transfers are significantly higher in Treatment 2 than in Treatment $1(p=0.050$, one-tailed test), since transfers were higher in each session in Treatment 2 than in any session in Treatment 1.

\footnotetext{
${ }^{14}$ Descriptions of the variables in these regressions are given at the bottom of these Tables. Note that Table 3 shows that receiving $h$ clearly increases transfers, as the coefficient on Variable income (200 if the individual received $h$ and 0 otherwise) is quite significant and implies that receiving $h$ increases the average transfer by about 44 units.
} 
In both Tables 3 and 4 , we see that a higher continuation probability substantially increases the transfers. Specifications (1) and (2) in Table 3 indicate that increasing the continuation probability from 0.8 to 0.9 increases transfers by about 18 units, while specifications (1) and (2) in Table 4 indicates that it raises the transfers made by people who receive $h$ by $16-21$ units.

A closer examination shows that there are significantly different patterns over time with the different continuation probabilities. The coefficient for $\delta=.9$ become insignificant in Tables 3 and 4 for specifications (3), which include an interaction term $\operatorname{Round}^{*} \delta=.9$. In specification (1) in both tables we see no significant time effect within a match but specifications (2) and (3) reveal different time effects depending on the continuation probability and ex ante equality. For instance, in Table 4, when $\delta=0.8$ and fixed incomes are equal, transfers decrease by 5.6 units per round within a match, while when $\delta=0.9$, transfers decrease by only 0.1 within a match; we see a similar pattern when fixed incomes are not equal, as well as in Table 3. Thus, transfers don't decline over a match when $\delta=0.9$, but do decline when $\delta=0.8$, and much of the effect of different continuation probabilities appears to stem from differences over the course of matches.

Question 2: Risk aversion. A second prediction of risk-sharing without commitment is that people who are more risk averse will engage in more risk sharing, so that we should observe higher transfers by more risk-averse individuals. Our initial investment question provides us with an estimate of individual attitude towards risk. As illustrated in Figure 2, we observed a large range of answers to the investment question.

[Figure 2 here]

In both Table 3 and 4, the coefficients on Investment (the amount invested in the risky investment) are significantly negative in all specifications. Since a larger investment in the risky 
asset indicates less risk aversion, a negative impact on the transfers is exactly what the model predicts. To be sure, subject in this experiments face some uncertainty about the risk aversion of their partner and are therefore playing a game of imperfect information. Individual's beliefs on her partner's risk aversion affect her choice of transfers too. Nevertheless, as long as these beliefs have a small support and are independent or positively correlated with own risk aversion, this should not affect our results. We conclude that a higher degree of risk aversion increases the transfer that one chooses when high and therefore increases risk sharing. Specification (1) in Tables 3 and 4 indicates that a person who chose to invest 30 would transfer 24.4 units more on average and 26.6 units more upon receiving $h$ than other person who chose to invest 80 . Specifications (2) and (3) in Table 4 indicate that the other person's investment in the risky asset also has a negative and substantial impact on the transfers made when high. The patterns are similar but not significant in Table 3 .

Question 3: The effect of inequality. Recall that the risk-sharing model predicts higher transfers with greater ex ante inequality for a large range of preferences. We do not find support for this outcome here. We can assess the overall effect of equality on transfers by looking at the effect of the fixed income. Indeed, recall that changes to an individual's fixed income are concurrent with changes in his partner's income. We find that average transfers with ex ante inequality are in fact lower than with ex ante equality (34.24 compared to 47.50). Table 3 indicates that total transfers are on average higher by 22.5 units with equality as opposed to inequality (twice the coefficient of D70 compared with the coefficient of D120); Table 4 
specification (1) shows that an $h$-receiving person in an equal match transfers 25.7 more than a person in an unequal match. ${ }^{15}$

We can supplement our regression analysis here by considering whether each individual made larger transfers on average with equality or inequality, since each person participated in both environments. It turns out that average transfers were higher for 60 people with equality and for 32 people with inequality, with no difference for the other two people. The binomial test on individual data finds this difference highly significant $(Z=2.92, p=0.004$, two-tailed test); using session-level data (see Appendix B), transfers are higher with ex ante equality than without it in every session, so we have statistical significance on this basis ( $p=0.032$, two-tailed test).

Question 4: Past transfers and time. Risk sharing requires reciprocal response. Tables 3 and 4 clearly show that the first transfer made by the individual's partner within a match has a strong positive effect on his transfers, and that this effect differs according to whether the partner had or not received $h$ in the first period. In Table 3 specification (1), we see that an additional 10 units of transfer in the first period by one's counterpart who had not received $h$ (Other's $1^{s t}$ transfer) increases an individual's average transfer in each period by 3.4 units; in Table 4, the corresponding figure is 4.3 units. Interestingly, the coefficient on Other's $1^{\text {st }}$ transfer $\mid h$ is significantly negative in Table 3, indicating that transfers made by an individual when he has not received $h$ are particularly effective, perhaps being interpreted as a form of signal. Specifications (2) and (3) highlight a gender effect, in that females respond more to the transfer made in the first period. A female subject who receives a small transfer from the other in the first period reduces her transfer more than a male subject does.

\footnotetext{
${ }^{15}$ There was not much difference in the transfers made by the person not receiving $h$ with equality (10.40) and inequality (9.20).
} 
We also see in Table 3 that there is a very different evolution of transfers over time within matches, depending on whether the individuals' fixed incomes are the same or not. The coefficient of Round $* D 70$ is significantly positive, and in specification (2) more than offsets the negative coefficient of Round. Thus, when the individuals have the same fixed income, transfers within a match are fairly flat over time. In contrast, transfers decrease over time when the fixed incomes differ. $^{16}$

Question 5: Beliefs. If transfers depend on past actions, we might also expect transfers to be affected by how one's expectations are met. In the first round of a couple of matches per session, we elicited the beliefs of subject who did not receive the 200 regarding the transfer they expect to receive from the other. We find that, out of 94 observations, $38 \%$ of them received more than they did expect, $9 \%$ received exactly what they expected and $53 \%$ received less than expected. These proportions do not differ significantly across gender.

Table 6 shows the effect of meeting individual's expectations or not on the transfers, as we include the difference between an individual's expectations and the transfer actually received. Bdiff takes values in $\{+1,0,-1\}$ if the transfer received earlier in the current match was respectively above, at, or below expectations. Clearly, its effect in the random-effects specifications is quite significant and positive on the transfers made by an individual. These results could be interpreted as the use of punishment following transfers lower than expected. It is interesting to see that the effect of the round within the match is not significant when we control for the difference between expectations and received transfers, so that we don't observe a pure time-decay effect (within a match) even in the $\delta=0.8$ treatment.

\footnotetext{
${ }^{16}$ We also find (not shown) that transfers significantly increase with a higher number of rounds in the previous match. This suggests that participants' views on the likely length of a match are sensitive to their own experience, despite the statements of mathematical expectations given in the instructions.
} 
Question 6: Gender Patterns. The average transfer by males was 28.9 while the average transfer by females was 22.0. ${ }^{17}$ Given that females are more risk averse than males in our experiment, ${ }^{18}$ we might have expected females to make higher transfers. However, we observe in specification (1) of both Tables 3 and 4 that, controlling for risk aversion, females make significantly smaller transfers. The coefficient on Female is much lower when we include the interaction term Round*Female, in specification (3), as it appears that transfers decrease over time relative to male transfers. We also mentioned earlier that females' transfers are more sensitive to the firs transfer received. The lower transfers by females results in a significantly lower net consumption for males $(Z=2.68, p=0.007$, using a Wilcoxon test on individual average consumption. ${ }^{19}$ Using session-level data (see Appendix B), we see that consumption is higher for females than for males in each of the six sessions, so a binomial test confirms statistical significance ( $p=0.032$, two-tailed test).

It is interesting to note that despite the mean transfer being lower for females, males are actually slightly more likely to choose to transfer zero when ahead, $29.8 \%$ versus $27.8 \%$. On the other hand, the average non-zero transfer made when ahead is higher for males than for females with each combination of continuation probability and fixed income.

\section{Discussion}

Our experiment provides evidence that is largely consistent with the model of risk sharing without commitment. Net positive transfers go from individuals receiving a high shock to those not receiving the high shock and these transfers substantially reduces the standard

\footnotetext{
${ }^{17}$ Note that each individual is unaware of the gender of the other person in the match.

${ }^{18}$ This gender investment result is extremely robust, as is discussed in Charness and Gneezy (2004).

${ }^{19}$ Note that this is not due to females having better draws; females comprised $56.4 \%$ of the population and females had the larger endowment $55.6 \%$ of the time.
} 
deviation of consumption; this could be considered insurance. A longer expected time horizon has a strong positive effect on transfers, as does a higher degree of risk aversion. None of these effects would be expected to arise if transfers were motivated purely by altruism or distributive preferences. As we also find that one's chosen transfer depends positively on the other party's first transfer and on receiving transfers that meet or exceed expectations, there is clear evidence of reciprocal relationships.

One may wonder whether the behavior we observe is really risk sharing or is simply a form of social preference. For example, models of utility such as Fehr and Schmidt (1999), Bolton and Ockenfels (2000) and Charness and Rabin (2002) all predict that, holding the total payoff constant, net transfers will go toward the person with the lower total income. Furthermore, since we observe reciprocal behavior, one might be tempted to conclude that we are observing a form of 'reciprocity'. However, this term has had many meanings in the literature, and one must be careful to clearly specify what is meant by it. We feel that reciprocity in its purest sense is not a strategic notion, but refers to a per se preference to help or hurt someone else due to one's perceptions of the other party's actions and motivation for these actions. ${ }^{20}$ Given the observed patterns of behavior, the reciprocal relationships we observe in our experiment instead seem the result of strategic considerations; nevertheless, one could also imagine preference-based behavior, based only on the individual's behavior when receiving $h$, that would also result in effective risk sharing.

To help interpret our results in the light of alternative interpretations, we present some predictions of the risk-sharing model and various models of social preferences in Table 7:

\footnotetext{
${ }^{20}$ Models of kindness-based reciprocity, such as Rabin (1993) and Dufwenberg and Kirchsteiger (2004), formalize this idea; also see Charness and Rabin (2002), Charness (2004), and Cox (2004) for discussions of this point.
} 
Table 7: Alternative models and predictions for transfers

\begin{tabular}{|c|c|c|c|c|c|}
\hline \multirow{2}{*}{ Issue } & \multicolumn{5}{|c|}{ Model } \\
\hline & Risk sharing & FS (1999) & CR (2002) & Rabin (1993) & DK (2004) \\
\hline Higher $\delta$ & Positive & No effect & No effect & No effect & No effect \\
\hline Higher risk aversion & Positive & No effect & No effect & No effect & No effect \\
\hline Higher past transfers & Positive & No effect & Positive $^{21}$ & Positive & Positive \\
\hline Ex ante inequality & Positive & No effect & No effect & No effect & No effect \\
\hline
\end{tabular}

Correct predictions are in bold.

The risk-sharing model correctly predicts three of the four observed effects, although it gets the sign wrong with respect to the effect of ex ante inequality; no other model makes more than one correct prediction. Thus, while we don't deny that other considerations such as altruism or social preferences could also be at play, the observed behavior suggest that the strategic considerations in our model of risk sharing without commitment are important for explaining the subjects' behavior. In particular, the positive correlations between transfers and $\delta$ and between transfers and risk aversion are strong pieces of evidence favoring this interpretation. ${ }^{22}$

We can compare the transfers observed in the experiment with the results of simulations of the model in Section 3. Table 8 compares the median observed transfers made when receiving $h$ for the low and high risk aversion group of subjects (second and fourth columns) with the transfers $\mathbf{t}^{*}$ defined by equations (4) if we assume that both individuals have a constant relative

\footnotetext{
${ }^{21}$ If lower transfers by the other party are seen as a form of misbehavior, one would then (partially) withdraw one's concern for the well-being of the other party and make smaller (or no) transfers to this party.

${ }^{22}$ For future research, one could examine the transfers that people would make in our experiment if matches did not last more than one round $\left(\delta^{-}\right.$. In this case, transfers would be motivated only by considerations such as altruism and social preferences. However notice that this would not provide a benchmark for the importance of altruism in the present experiments, as altruism and risk sharing in repeated game can interact in non-trivial ways. Increasing altruism can even decrease the amount of transfers (see Foster and Rozensweig 2001).
} 
risk aversion utility function, $\mathrm{u}(\mathrm{c})=\frac{1}{1-\rho} \mathrm{c}^{1-\rho}$ (first and third columns). The simulated transfers are computed using the median coefficient of relative risk aversion $\rho$ implied by the choice of investment of the high risk aversion $(\rho=0.324)$ and the low risk aversion $(\rho=0.174)$ groups. $^{23}$

\section{Table 8: Predicted and actual transfers}

\begin{tabular}{|c|c|c|c|c|}
\hline & \multicolumn{2}{|c|}{$\delta=0.8$} & \multicolumn{2}{|c|}{$\delta=0.9$} \\
\hline & Predicted & Actual & Predicted & Actual \\
\hline \multicolumn{5}{|c|}{ Equality $\left(y_{1}=y_{2}=70\right)$} \\
\hline$\rho=0.324$ & $t *_{1}=t *_{2}=12$ & 20 & $t^{*}{ }_{1}=t *_{2}=100$ & 70 \\
\hline$\rho=0.174$ & $t^{*}{ }_{1}=t *_{2}=0$ & 15 & $t^{*}{ }_{1}=t^{*}{ }_{2}=31$ & 20 \\
\hline \multicolumn{5}{|c|}{ Inequality $\left(y_{1}=120, y_{2}=20\right)$} \\
\hline$\rho=0.324$ & $t^{*} *_{1}=32, t_{2}{ }_{2}=37$ & $t_{1}=13, t_{2}=18$ & $t^{*} *_{1}=98, t_{2}^{*}=102^{\dagger}$ & $t_{1}=57, t_{2}=39$ \\
\hline$\rho=0.174$ & $t^{*}=0, t_{2}{ }_{2}=0$ & $t_{1}=8, t_{2}=0$ & $t *_{1}=40, t *_{2}=43$ & $t_{1}=8, t_{2}=24$ \\
\hline
\end{tabular}

†There is an interval of first-best allocations that is feasible; this is the most equal.

Overall, we note that transfers are limited in a way that is consistent with the modest levels of risk aversion exhibited by the participants. ${ }^{24}$ With equality and $\delta=0.8$, predicted transfers are a bit lower than what is observed, while with equality and $\delta=0.9$, this pattern is reversed. We see that although there is a reasonably close fit between the predictions and the observed transfers for the equal sharing, with inequality the actual transfers are substantially less than the predicted levels.

\footnotetext{
${ }^{23}$ Assuming constant relative risk aversion utility, the coefficient of risk aversion is given by the following formula:

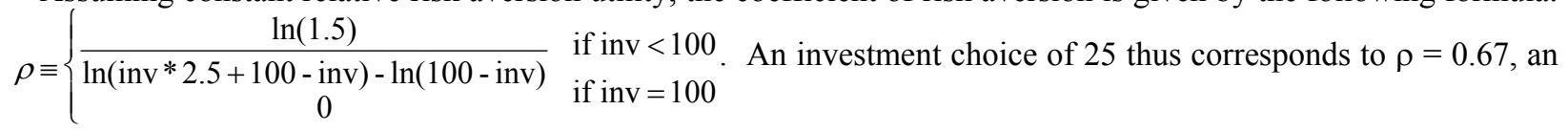
investment choice of 50 corresponds to $\rho=0.32$, and an investment choice of 75 corresponds to $\rho=0.19$.

${ }^{24}$ These levels of risk aversion are similar to the ones found in other experiments (see among others Biswanger 1980 and Goeree et al. 2000).
} 
For utility functions of the HARA class (hyperbolic absolute risk aversion), inequality should improve risk sharing and not decrease it; with decreasing risk aversion (as traditionally assumed) we should observe individuals with lower fixed income making higher transfers when receiving $h$ than individuals with higher fixed income make when receiving $h$, as the poorest agent trades mean consumption in exchange for insurance. Yet, in our experiment we observe that high-fixed-income individuals actually transfer more than low-fixed-income individuals. In fact, perhaps surprisingly, none of the other models predict the result that ex ante equality leads to higher transfers. This consideration is irrelevant for the Fehr and Schmidt (1999) model, the Charness and Rabin (2002) model, and the pure-reciprocity models. ${ }^{25}$

Thus, we must look for another explanation. In some sense, equal fixed payoffs may make coordinating on reciprocal transfers easier. Table 4 clearly suggests that the inequality results stem from people with low fixed income making substantially lower transfers. This may reflect the fact that even when the person with the low fixed income receives $h$, he or she is nevertheless poorer in expected terms during the remainder of the match. Since we pay for only one period, this story might not apply, but it could still influence behavior. In any event, by this logic we should also see substantially higher transfers with the high fixed income than with equal fixed incomes, and we don't. Perhaps one views one's 'local' wealth in a self-serving manner, and this divergence in perspectives makes risk sharing more difficult.

In another sense equal fixed payoffs make it easier for one to identify with the other person and interpret the transfers made. Previous studies have shown that participants in

\footnotetext{
${ }^{25}$ To see this for the Fehr and Schmidt (1999) model, note that the only factor involved is the expected difference in ex post payoffs; this will always be 200 with ex ante equality, and will be either 100 or 300 with ex ante inequality. But since this is on average 200 and the model is linear, there should be no difference for these cases. The relevant factor in the Charness and Rabin (2002) model is the minimum payoff, rather than the difference in payoffs, but this also averages the same in the two cases. All of the distributional models make the clear prediction that an individual with the highest fixed income (120) should make greater transfers than an individual with medium fixed income (70), and this is not the case (see Table 2, for example).
} 
experiments are prone to identification or 'solidarity' with an arbitrary group. Tajfel, Billig, Bundy, and Flament (1970) find that subjects treat people who have been designated to be part of their 'group' quite differently than people not in their group. Charness, Rigotti, and Rustichini (2003) achieve strong group identification affecting play in Battle-of-the-Sexes and Prisoner's Dilemma games. If, as Akerlof and Kranton (2000, p. 748) assert, “a person's self is associated with different social categories and how people in these categories should behave," perhaps it is reasonable to expect that people who are ex ante equal to more readily form reciprocal relationships and higher transfers.

\section{CONCLUSION}

In this paper, we test experimentally for risk sharing without commitment and some of its implications. The experiment was designed to fit as closely as possible the models of risk sharing without commitment used in the literature, and, following the literature, we focused on the constrained optimal equilibrium. While our income process and experimental setting are simplified, we feel that this approach is ideally suited as a first laboratory test of risk sharing without commitment or enforcement.

We find evidence of risk sharing behavior, including significant support for some important features of the models of risk sharing without commitment. Net transfers flow from the individual who received a good shock in the period to the other, whether or not the fixed incomes are the same. Both a higher continuation probability and a higher degree of risk aversion strongly and significantly increase the level of risk sharing that individuals choose. Moreover, a form of reciprocal behavior is shown to be important for risk sharing: The higher the first transfer made by an individual's partner, the higher the individual's eventual transfers. 
We also find that beliefs matter, in that how actual transfers compare to expected transfers plays a role in subsequent transfers. However, in contrast with the model's predictions, inequality between individuals in a match actually decreases risk sharing, suggesting the influence of some form of social cohesion or identification process.

Finally, we also observe that the person with less income in a round often makes a small positive transfer to the other person. Perhaps such a transfer is seen as a signal of intent; such transfers in the first round of a match are (dollar-for-dollar) more effective in increasing one's counterpart's transfers than transfers made in the first round when receiving the larger income.

While we have provided evidence that is consistent with risk sharing in the laboratory, our study is only a first step towards examining how this behavior might evolve and how it might be sensitive to institutional considerations. Next steps include utilizing a more realistic income process and allowing communication between the parties. We feel that this is a promising area for future research, as informal risk sharing is a critical feature of the economy in many contemporary environments.

\section{REFERENCES}

Akerlof, G. and R. Kranton (2000), "Economics and Identity,” Quarterly Journal of Economics, 115, 715-753.

Axelrod, R. (1980), "More Effective Choice in the Prisoner's Dilemma," Journal of Conflict Resolution, 24, 379-403.

Barr, A. and G. Genicot (2007), "Risk Pooling, Commitment, and Information: An Experimental Test," mimeo.

Biswanger, H. (1981) "Attitudes Towards Risk: Theoretical Implications of an Experiment in Rural India," Economic Journal 91, 867-890.

Bolton, G., and A. Ockenfels (2000), "ERC - A Theory of Equity, Reciprocity, and Competition," American Economic Review 90, 166-193.

Bone, J., J. Hey and J. Suckling (2004), “A Simple Risk-Sharing Experiment," Journal of Risk and Uncertainty 28, 23-38.

Camerer, C. and T. Ho (1994), "Violations of Betweenness Axiom and Nonlinearity in Probability," Journal of Risk and Uncertainty 8, 167-196.

Cason, T. (1995), "Cheap Talk Price Signaling in Laboratory Markets," Information Economics and Policy 7, 183-204. 
Charness, G. and N. Garoupa (2000), "Reputation, Honesty, and Efficiency with Insider Information: An Experiment," Journal of Economics and Management Strategy 9, 425451

Charness, G. and U. Gneezy (2004), "Gender and Risk Attitudes in Investment Decisions," mimeo.

Charness, G. and M. Rabin (2002), "Understanding Social Preferences with Simple Tests," Quarterly Journal of Economics 117, 817-868.

Charness, G., L. Rigotti, and A. Rustichini (2003), "They are Watching You: Audience Effects in Economic Institutions," mimeo.

Coate, S. and M. Ravallion (1993), "Reciprocity without Commitment: Characterization and Performance of Informal Insurance Arrangements," Journal of Development Economics 40, 1-24.

Cox, J. (2004), "How to Identify Trust and Reciprocity: Implications of Game Triads and Social Contexts," Games and Economic Behavior, 46, 260-81.

Croson, R. and U. Gneezy (2004), "Gender Differences in Preferences," mimeo.

Dal Bó, P. (2005), "Cooperation under the Shadow of the Future: Experimental Evidence from Infinitely Repeated Games," forthcoming American Economic Review.

Dawes. R., J. McTavish and H. Shaklee (1977), "Behavior, Communication, and Assumptions about Other People's Behavior in a Common Dilemma Situation," Journal of Personality and Social Psychology 35, 1-11.

Deaton, A. (1992), Understanding Consumption, Oxford: Clarendon Press.

Dercon S. and P. Krishnan (2000), "In Sickness and in Health: Risk sharing within households in rural Ethiopia," Journal of Political Economy 108, 688-727.

Dubois, P. and E. Ligon (2004), "Incentives and Nutrition for Rotten Kids: Intra-Household Food Allocation in the Philippines," mimeo.

Fehr, E. and K. Schmidt (1999), "A Theory of Fairness, Competition, and Cooperation," Quarterly Journal of Economics 114, 517-868.

Foster, A. and M. Rosenzweig (2001), "Imperfect Commitment, Altruism, and the Family: Evidence from Transfer Behavior in Low-Income Rural Areas," Review of Economics and Statistics 83, 389-407.

Frank, R., T. Gilovich, and D. Regan (1993), "The Evolution of One-shot Cooperation," Ethology and Sociobiology 14, 247-256.

Genicot, G. (2007), “Does Inequality Help Risk Sharing?,” mimeo. [http://www.georgetown.edu/faculty/gg58/IIdraft.pdf]

Genicot, G. and D. Ray (2003) "Endogenous Group Formation in Risk-Sharing Arrangements," Review of Economic Studies 70 (1), 87-113.

Gertler, P. and J. Gruber (2002), "Insuring Consumption Against Illness," American Economic Review 92, 51-70.

Gneezy, U., and J. Potters (1997), “An Experiment on Risk Taking and Evaluation Periods," Quarterly Journal of Economics, 112, 631-645

Goeree, J.K., C.A. Holt and T.R. Palfrey (2000) "Risk Averse Behavior in Asymmetric Matching Pennies Games," mimeo.

Grimard, F. (1997), "Household Consumption Smoothing through Ethnic Ties: Evidence from Côte D'Ivoire," Journal of Development Economics 53, 391-422.

Jalan, J. and M. Ravallion (1999), "Are the Poor Less Well Insured? Evidence on Vulnerability to Income Risk in Rural China," Journal of Development Economics 58, 61-81. 
Kahn, A., J. Hottes, and W. Davis (1971), “Cooperation and Optimal Responding in the Prisoner's Dilemma Game: Effects of Sex and Physical Attractiveness," Journal of Personality and Social Psychology 17, 267-279.

Kimball, M. (1988), "Farmer Cooperatives as Behavior Toward Risk," American Economic Review 78, 224-232.

Kletzer, K. and B. Wright (2000), "Sovereign Debt as Intertemporal Barter," American Economic Review 90, 621-639.

Kocherlakota, N. (1996), "Implications of Efficient Risk Sharing without Commitment," Review of Economic Studies 63(4), 595-609.

Ligon, E., J. Thomas, and T. Worrall (2002), "Mutual Insurance and Limited Commitment: Theory and Evidence in Village Economies," Review of Economic Studies 69, 209-44.

Mack, D., P. Auburn, and G. Knight (1971), "Sex Role Identification and Behavior in a Reiterated Prisoner's Dilemma Game," Psychonomic Science 24, 280-282.

Murnighan, J. and A. Roth (1983), "Expecting Continued Play in Prisoner's Dilemma Games: A Test of Several Models," Journal of Conflict Resolution 27, 279-300.

Orbell, J., R. Dawes, and P. Schwartz-Shea (1994), "Trust, Social Categories and Individuals: The Case of Gender," Motivation and Emotion 18, 109-128.

Rabin M. (2002), "Risk Aversion and Expected Utility Theory: a Calibration Theorem," Econometrica 68, 1281-1292.

Rapoport, A. and A. Chammah (1965), "Sex Differences in Factors Contributing to the Level of Cooperation in a Prisoner's Dilemma Game," Journal of Personality and Social Psychology 2, 831-838.

Ross, L., D. Greene and P. House (1977), “The False Consensus Effect: An Egocentric Bias in Social Perception and Attribution Processes", Journal of Experimental Social Psychology, 13, 279-301.

Roth, A. and J. Murnighan (1978), "Equilibrium Behavior and Repeated Play of the Prisoner's Dilemma," Journal of Mathematical Psychology 17, 189-198.

Selten, R., and A. Ockenfels (1998), “An Experimental Solidarity Game," Journal of Economic Behavior and Organization 34, 517-519.

Selten, R., A. Sadrieh, and K. Abbink (1999), "Money Does Not Induce Risk Neutral Behavior, But Binary Lotteries Do Even Worse," Theory and Decision 46, 211-49.

Siegel, S. and N. Castellan Jr. (1988), Nonparametric Statistics for the Behavioral Sciences, McGraw-Hill International Editions.

Tajfel, H., M. Billig, R. Bundy and C. Flament (1970), "Social Categorization and Intergroup Behavior," European Journal of Social Psychology 1, 149-78.

Tedeschi, J., D. Hiester and J. Gahagan (1969), "Trust and the Prisoner's Dilemma Game, Journal of Social Psychology 79, 43-50.

Thomas, J. and T. Worrall (1994), "Informal Insurance Arrangements in Village Economies," Liverpool Research Papers in Economics and Finance 9402.

Townsend, R. (1994), "Risk and Insurance in Village India," Econometrica 62, 539-91.

Townsend, R. (1995), "Consumption Insurance: An Evaluation of Risk-Bearing Systems in LowIncome Economies," Journal of Economic Perspectives 9, 83-102.

Udry, C. (1994), "Risk and Insurance in a Rural Credit Market: An Empirical Investigation in Northern Nigeria," Review of Economic Studies 61, 495-526.

Udry, C. (1995), "Risk and Saving in Northern Nigeria," American Economic Review 85, 12871300. 


\section{Appendix A}

\section{Effect of Risk Aversion}

Using the model in Section 3, assume that individual i has a constant relative risk aversion $\left(\right.$ CRRA) utility $\mathrm{u}_{i}(\mathrm{c})=\frac{1}{1-\rho} \mathrm{c}^{1-\rho}$, where $\rho$ is the Arrow-Pratt coefficient of relative risk aversion.

Proposition: An increase in an individual's risk aversion $\rho$ relaxes the individual's incentive constraint.

Proof. With a CRRA utility, agent $i$ 's incentive constraint (IC) in (4) becomes

$$
\left(1-\frac{\delta}{2}\right)\left(y_{i}+h-t_{i}^{*}\right)^{1-\rho}+\frac{\delta}{2}\left(y_{i}+t_{j}^{*}\right)^{1-\rho}-\left(1-\frac{\delta}{2}\right)\left(y_{1}+h\right)^{1-\rho}-\frac{\delta}{2}\left(y_{1}\right)^{1-\rho}=0, \quad j \neq i .
$$

To simplify notation let $c_{h}=y_{i}+h-t_{i}{ }^{*}, c_{l}=y_{i}+t_{j}{ }^{*}, y_{l}=y_{i}$ and $y_{h}=y_{i}+h$. An increase in individual i's risk aversion $\rho$ increases the left-hand-side of this equality, thereby relaxing the constraint, if

$$
-\left(1-\frac{\delta}{2}\right) \frac{1}{1-\rho} \ln c_{h}\left(c_{h}\right)^{1-\rho}-\frac{\delta}{2} \frac{1}{1-\rho} \ln c_{l}\left(c_{l}\right)^{1-\rho}+\left(1-\frac{\delta}{2}\right) \ln y_{h} \frac{1}{1-\rho}\left(y_{h}\right)^{1-\rho}+\frac{\delta}{2} \frac{1}{1-\rho} \ln y_{h}\left(y_{l}\right)^{1-\rho}>0 .
$$

We now show that this inequality holds. To do so, it is useful to define

$$
F(\underline{c}, \bar{c}) \equiv-\left(1-\frac{\delta}{2}\right) \frac{1}{1-\rho} \ln \bar{c}(\bar{c})^{1-\rho}-\frac{\delta}{2} \frac{1}{1-\rho} \ln \underline{c}(\underline{c})^{1-\rho} .
$$

We call an "IC-neutral change" a simultaneous decrease by one unit in $\bar{c}$ and increase by

$$
\frac{(1-\delta / 2)}{\delta / 2} \frac{\bar{c}^{-\rho}}{\underline{c}^{-\rho}} \text { in } \underline{c} . \text { Such a change keeps }-\left(1-\frac{\delta}{2}\right) \frac{1}{1-\rho}(\bar{c})^{1-\rho}-\frac{\delta}{2} \frac{1}{1-\rho}(\underline{c})^{1-\rho} \text { constant. }
$$

The effect of an $I C$-neutral change on $F(\underline{c}, \bar{c})$ is given by

$$
\begin{aligned}
& \left(1-\frac{\delta}{2}\right) \frac{1}{1-\rho}(\bar{c})^{-\rho}+\left(1-\frac{\delta}{2}\right) \ln \bar{c}(\bar{c})^{-\rho}-\left(\frac{1}{1-\rho} \frac{\delta}{2}(\underline{c})^{-\rho}+\frac{\delta}{2} \ln \underline{c}(\underline{c})^{-\rho}\right) \frac{(1-\delta / 2)}{\delta / 2} \frac{\bar{c}^{-\rho}}{\underline{c}^{-\rho}} \\
& =\left(1-\frac{\delta}{2}\right) \bar{c}^{-\rho}(\ln \bar{c}-\ln \underline{c}),
\end{aligned}
$$

which is clearly strictly positive for $\bar{c}>\underline{c}$.

Finally, notice that (5) can be written as $F\left(c_{l}, c_{h}\right)>F\left(y_{l}, y_{h}\right)$. This inequality holds since we can go from $\left(y_{l}, y_{h}\right)$ to $\left(c_{l}, c_{h}\right)$ following a sequence of $I C$-neutral changes and $c_{l} \leq c_{h}$. 


\section{Discounting}

Consider a subject participating in the experiment. Assume that there are $m$ matches left and that, $\bar{T}$ rounds have already been realized: $\underline{T}$ over all previous matches and $T$ rounds in the current match.

Our subject knows that with a probability $(1-\delta) \delta^{\mathrm{j}}$ the current match will last $\mathrm{j}$ more rounds for any $\mathrm{j} \in\{0,1,2 \ldots\}$. If it lasts $j$ more rounds, any round $t$ of the current match for $t \in\{1, . . T+j\}$ with utility of consumption $\mathrm{u}\left(\mathrm{c}_{\mathrm{t}}\right)$ has a probability $\pi_{\bar{T}, \mathrm{j}}=\sum_{l=0}^{\infty} p_{m}(l) \frac{1}{\bar{T}+j+l}$ to be selected for her payoff. Notice that if only one match was played $T=\bar{T}$ and $\pi_{T, \mathrm{j}}$ is just $\frac{1}{T+j}$.

This implies that, within this match, our subject has an expected utility of: ${ }^{26}$

$$
\begin{aligned}
\mathrm{U}_{\bar{T}, \mathrm{~T}} & =(1-\delta) \pi_{\bar{T}, 0} \sum_{t=1}^{T} \mathrm{u}\left(\mathrm{c}_{\mathrm{t}}\right)+(1-\delta) \delta \pi_{\bar{T}, 1} \sum_{t=1}^{T+1} \mathrm{u}_{\mathrm{i}}\left(\mathrm{c}_{\mathrm{t}}\right)+\ldots+(1-\delta) \delta^{j} \pi_{\bar{T}, j} \sum_{t=1}^{T+j} \mathrm{u}\left(\mathrm{c}_{\mathrm{t}}\right)+\ldots \\
& =\sum_{t=1}^{T-1}\left(\sum_{j=0}^{\infty}(1-\delta) \delta^{j} \pi_{\bar{T}, j}\right) \mathrm{u}\left(\mathrm{c}_{\mathrm{t}}\right)+E_{t} \sum_{t=T}^{\infty}\left(\sum_{j=t-T}^{\infty}(1-\delta) \delta^{j} \pi_{\bar{T}, j}\right) \mathrm{u}\left(\mathrm{c}_{\mathrm{t}}\right)
\end{aligned}
$$

Using the punishment of Section 3, the expected utility of this agent if she deviates is instead

$$
\mathrm{U}_{\bar{T}, T}^{\mathrm{D}}=\sum_{t=1}^{T-1}\left(\sum_{j=0}^{\infty}(1-\delta) \delta^{j} \pi_{\bar{T}, j}\right) \mathrm{u}\left(\mathrm{c}_{\mathrm{t}}\right)+E_{T} \sum_{t=T}^{\infty}\left(\sum_{j=t-T}^{\infty}(1-\delta) \delta^{j} \pi_{\bar{T}, j}\right) \mathrm{u}_{\left(\mathrm{y}_{\mathrm{t}}\right)}
$$

It follows that the incentive constraint is given by

$$
E_{T} \sum_{t=T}^{\infty} \widetilde{\beta}_{t-T, \widetilde{T}}\left(\mathrm{u}\left(\mathrm{c}_{\mathrm{t}}\right)-\mathrm{u}\left(\mathrm{y}_{\mathrm{t}}\right)\right) \geq 0
$$

where $\widetilde{\beta}_{k, \bar{T}}=\left(\sum_{j=k}^{\infty}(1-\delta) \delta^{j} \pi_{\bar{T}, j}\right)$ and where the expectation is conditional on knowing the realization up to time $T$.

Let $\beta_{j, \bar{T}}=\widetilde{\beta}_{j, \bar{T}} / \widetilde{\beta}_{0, \bar{T}}$ for $j \geq 0$ and let $\beta_{\bar{T}}=\beta_{1, \bar{T}}$. We can rewrite the incentive constraint (6) as

$$
\left(\mathrm{u}_{\mathrm{i}}\left(\mathrm{c}_{\mathrm{T}}\right)-\mathrm{u}_{\mathrm{i}}\left(\mathrm{y}_{\mathrm{T}}\right)\right)+E \sum_{j=1}^{\infty} \beta_{j, \bar{T}}\left(\mathrm{u}_{\mathrm{i}}\left(\mathrm{c}_{\mathrm{T}+\mathrm{j}}\right)-\mathrm{u}_{\mathrm{i}}\left(\mathrm{y}_{\mathrm{T}+\mathrm{j}}\right)\right) \geq 0 .
$$

\footnotetext{
${ }^{26}$ Note that since subjects are paired with a new subject when a match ends, we can focus on the "within match" utilities when considering the incentives to deviate.
} 


\section{Observations:}

[1] $\beta_{j, T}$ is increasing in $\delta$ for all $\mathrm{j}$ and T so that a higher $\delta$ relaxes the incentive constraint (7) [2] $\beta_{j, T} \approx \delta^{j}$.

It is easy to check that $\frac{\widetilde{\beta}_{k+1, \bar{T}}}{\widetilde{\beta}_{k, \bar{T}}}=\frac{\widetilde{\beta}_{1, \bar{T}+k}}{\widetilde{\beta}_{0, \bar{T}+k}}=\beta_{T+k}$ and therefore that, for $\mathrm{j}>0$,

$$
\beta_{j, T}=\frac{\widetilde{\beta}_{j, T}}{\widetilde{\beta}_{0, T}}=\frac{\widetilde{\beta}_{1, T}}{\widetilde{\beta}_{0, T}} \frac{\widetilde{\beta}_{2, T}}{\widetilde{\beta}_{1, T}} \ldots \frac{\widetilde{\beta}_{j, T}}{\widetilde{\beta}_{j-1, T}}=\beta_{T} \beta_{T+1} \ldots \beta_{T+j-1}=\prod_{t=T}^{T+j-1} \beta_{t} .
$$

Now notice that

$$
\beta_{t}=\frac{\sum_{j=2}^{\infty}(1-\delta) \delta^{j} \pi_{t, j}}{\sum_{j=1}^{\infty}(1-\delta) \delta^{j} \pi_{t, j}}=1-\frac{(1-\delta) \delta \pi_{t, 1}}{\sum_{j=1}^{\infty}(1-\delta) \delta^{j-1} \pi_{t, j}}=1-\frac{1}{\sum_{j=1}^{\infty} \delta^{j-1} \frac{\pi_{t, j}}{\pi_{t, 1}}}=1-\frac{1}{\sum_{j=0}^{\infty} \delta^{j} \frac{\pi_{t, j+1}}{\pi_{t, 1}}}
$$

First $\beta_{t}$ is clearly increasing in $\delta$ and therefore $\beta_{j, T}$ in (8) is too.

Since $\delta>0$ and $\frac{\pi_{t, j+1}}{\pi_{t, 1}}<1$ for $\mathrm{j}>0$, it follows that $\sum_{j=0}^{\infty} \delta^{j} \frac{\pi_{t, j+1}}{\pi_{t, 1}}<\frac{1}{1-\delta}$ and that $\beta_{t}<\delta$. For large $t$ or $m$ (the number of matches) $\frac{\pi_{t, j+1}}{\pi_{t, 1}}$ tends to 1 so $\beta_{t}$ tends to $\delta$ and $\beta_{j, T}$ tends to $\delta^{j}$. 


\section{APpENDiX B}

\section{Instructions}

Welcome to our experiment. For showing up on time, we will pay you a $\$ 5$ show-up fee. In addition, you may receive additional earnings as the result of the outcomes in the experimental session. Today's session will take about an hour.

To begin, we ask you to complete a brief questionnaire. The body of the session will be comprised of a number of segments. In each of these segments, each participant will be matched with one other person. Each segment is comprised of an uncertain number of periods. The number of periods in a segment is determined as follows: After each period, the computer will 'roll a die' (for the entire room) to see whether another period will follow, with a 90\% chance that another period will follow, and a $10 \%$ chance that the segment ends immediately. The computer will 'roll the die' after every period. With this continuation probability, the expected number of subsequent periods in a segment, at any point in time, is 9 .

When the segment ends (10\% chance after each period), all participants will be randomly rematched with other participants for the next segment. We anticipate that there will be approximately 7 segments in the session, but this will vary according to how many periods there are in the segments - we aim to complete the session in about an hour.

In each segment, you and the person with whom you are matched will receive income. This income is composed of a fixed portion and an amount (200) that is added to the fixed income for that period for one of the people in each match; the person receiving this extra amount is randomly chosen in each pair for every period of the segment. The fixed portions will not vary during the segment, but will change from segment to segment; these fixed portions may or not be the same for the two people matched. In all cases, this fixed portion will be considerably smaller than the 200 units that are randomly assigned.

In the beginning of the period, you will learn your fixed income, the fixed income of the person with whom you are paired, and who received the extra 200 in the period. At this point, you choose to transfer money to the other person. This amount must be non-negative and no more than the total income you received in that period. The other person in your match simultaneously chooses to transfer money to you, subject to the same restrictions on the amount to be transferred. The designated amounts are then transferred, and the computer then determines whether another period follows in this segment. You will see a history of the income and transfers for each previous period in that segment.

Thus, you will be involved in many periods. We wish to make it clear that only one of these periods will be chosen at random for conversion to real dollars, at the rate of 17 experimental units to one cash dollar.

Let's take an example. Assume that your fixed income be 50 and that you are matched with someone whose fixed income is 90 . In each round, either you get an additional 200 (50\% chance) or the person with whom you are matched gets an additional 200 (50\% chance). If in this round 
the other person receives this 200, your total income is 50 while his or her total income is 290 . Now, you and the person with whom you are matched decide on transfers. Suppose you transfer $x$ to the other person while he or she transfers $y$ to you; then your "income net of transfer" or "consumption" for this round is 50-x+y while his "income net of transfer" or "consumption" for this round is $290-y+x$. If this round happens to be the one selected to count for actual payoffs, these are your and your match's payoffs for the experiment. For instance if $x=1$ and $y=61$ then your payoff would be 110 and your match's payoff would be 230 .

At some points along the way, you will be asked for some information about your decisions and/or your expectations.

The history of income and transfers for the current match appears on your screen. By pressing the "full view" button you can also review the history of your past matches.

At the end of the experiment, one period will be chosen at random for payment. The screen will state your earnings. When you have completed a short questionnaire on your demographics, we will distribute receipts forms for participants to sign, and will pay people individually and privately.

We highly encourage clarifying questions. Thank you for your participation. 


\section{Appendix C}

SESSION DETAILS

\begin{tabular}{|c|c|c|c|c|}
\hline Session & Cont. probability & \# of Participants & \# of Matches & \# of Rounds \\
\hline 1 & 0.8 & 16 & 10 & 41 \\
\hline 2 & 0.8 & 16 & 10 & 26 \\
\hline 3 & 0.8 & 12 & 10 & 32 \\
\hline 4 & 0.9 & 14 & 7 & 83 \\
\hline 5 & 0.9 & 18 & 7 & 36 \\
\hline 6 & 0.9 & 18 & 7 & 47 \\
\hline
\end{tabular}

\section{SESSION-LEVEL DATA}

Transfer

\begin{tabular}{|c|c|c|}
\hline Session & No $h$ & Yes $h$ \\
\hline 1 & 5.12 & 26.54 \\
\hline 2 & 7.65 & 22.28 \\
\hline 3 & 6.41 & 20.43 \\
\hline 4 & 13.61 & 64.08 \\
\hline 5 & 13.62 & 43.31 \\
\hline 6 & 7.72 & 34.20 \\
\hline
\end{tabular}

No $h$ and Yes $h$ refer to whether an individual received the shock of 200

\begin{tabular}{|c|c|}
\hline Fixed $=70$ & Fixed $\neq 70$ \\
\hline 19.14 & 13.92 \\
\hline 16.02 & 14.41 \\
\hline 16.11 & 11.04 \\
\hline 40.96 & 35.80 \\
\hline 34.21 & 24.81 \\
\hline 21.92 & 19.95 \\
\hline
\end{tabular}

\begin{tabular}{|c|c|}
\hline Male & Female \\
\hline 158.18 & 175.37 \\
\hline 157.14 & 191.44 \\
\hline 168.71 & 170.92 \\
\hline 162.98 & 179.42 \\
\hline 169.58 & 170.27 \\
\hline 167.79 & 171.10 \\
\hline
\end{tabular}
refer to whether the fixed income was 70 for each person in the pair (ex ante equality) or not (inequality). 
Table 3 - Determinants of Transfers (all transfers)

\begin{tabular}{|c|c|c|c|}
\hline & $\begin{array}{c}\text { (1) } \\
\text { Tobit, re }\end{array}$ & $\begin{array}{c}(2) \\
\text { Tobit, re }\end{array}$ & $\begin{array}{c}(3) \\
\text { Tobit, re }\end{array}$ \\
\hline Investment & $\begin{array}{c}-0.487 \\
{[0.048]^{* * *}}\end{array}$ & $\begin{array}{c}-0.471 \\
{[0.056]^{* * *}}\end{array}$ & $\begin{array}{c}-0.463 \\
{[0.056]^{* * *}}\end{array}$ \\
\hline Female & $\begin{array}{c}-6.334 \\
{[2.319]^{* * *}}\end{array}$ & $\begin{array}{c}-9.482 \\
{[2.754]^{* * *}}\end{array}$ & $\begin{array}{c}-6.563 \\
{[3.508]^{*}}\end{array}$ \\
\hline Other's $1^{\text {st }}$ transfer & $\begin{array}{c}0.344 \\
{[0.059]^{* * *}}\end{array}$ & $\begin{array}{c}0.251 \\
{[0.068]^{* * *}}\end{array}$ & $\begin{array}{c}0.249 \\
{[0.069]^{* * *}}\end{array}$ \\
\hline Other's $1^{\text {st }}$ transfer $\mid h$ & $\begin{array}{c}-0.150 \\
{[0.055]^{* * *}}\end{array}$ & $\begin{array}{c}-0.156 \\
{[0.056]^{* * *}}\end{array}$ & $\begin{array}{c}-0.152 \\
{[0.056]^{* * *}}\end{array}$ \\
\hline$\delta=.9$ & $\begin{array}{c}18.248 \\
{[2.904]^{* * *}}\end{array}$ & $\begin{array}{c}18.414 \\
{[2.960]^{* * *}}\end{array}$ & $\begin{array}{c}6.618 \\
{[4.116]}\end{array}$ \\
\hline D 70 & $\begin{array}{c}22.109 \\
{[2.078]^{* * *}}\end{array}$ & $\begin{array}{c}17.313 \\
{[2.685]^{* * *}}\end{array}$ & $\begin{array}{c}16.891 \\
{[2.680]^{* * *}}\end{array}$ \\
\hline D120 & $\begin{array}{c}23.673 \\
{[2.445]^{* * *}}\end{array}$ & $\begin{array}{c}24.494 \\
{[2.454]^{* * *}}\end{array}$ & $\begin{array}{c}24.526 \\
{[2.469]^{* * *}}\end{array}$ \\
\hline Variable Income & $\begin{array}{c}0.224 \\
{[0.008]^{* * *}}\end{array}$ & $\begin{array}{c}0.224 \\
{[0.008]^{* * *}}\end{array}$ & $\begin{array}{c}0.223 \\
{[0.008]^{* * *}}\end{array}$ \\
\hline Round & $\begin{array}{c}-0.215 \\
{[0.164]}\end{array}$ & $\begin{array}{c}-0.951 \\
{[0.294]^{* * *}}\end{array}$ & $\begin{array}{c}-4.689 \\
{[0.945]^{* * *}}\end{array}$ \\
\hline Sex* other's $1^{\text {st }}$ transfer & & $\begin{array}{c}0.144 \\
{[0.050]^{* * *}}\end{array}$ & $\begin{array}{c}0.141 \\
{[0.050]^{* * *}}\end{array}$ \\
\hline Other's invest & & $\begin{array}{c}-0.010 \\
{[0.043]}\end{array}$ & $\begin{array}{c}-0.006 \\
{[0.044]}\end{array}$ \\
\hline Female other & & $\begin{array}{c}2.684 \\
{[1.715]}\end{array}$ & $\begin{array}{c}2.929 \\
{[1.720]^{*}}\end{array}$ \\
\hline Round*D70 & & $\begin{array}{c}0.986 \\
{[0.334]^{* * *}}\end{array}$ & $\begin{array}{c}0.774 \\
{[0.335]^{* *}}\end{array}$ \\
\hline Round $* \delta=.9$ & & & $\begin{array}{c}4.220 \\
{[0.940]^{* * *}}\end{array}$ \\
\hline Round*Female & & & $\begin{array}{c}-0.387 \\
{[0.322]}\end{array}$ \\
\hline Constant & $\begin{array}{c}-18.668 \\
{[4.108]^{* * *}}\end{array}$ & $\begin{array}{c}-16.061 \\
{[4.551]^{* * *}}\end{array}$ & $\begin{array}{c}-7.234 \\
{[5.415]}\end{array}$ \\
\hline
\end{tabular}

Observations: 1661. Number of unique identifiers for each individual: 94 . Standard errors are in brackets. $*$, ** and $* * *$ mean significant at $10 \%, 5 \%$ and $1 \%$, respectively, two-tailed tests. "re" stands for random effects. Investment \& other's invest are the respective investments for the individual \& the other person in the pair; D70 \& D120 are dummies for fixed income of $70 \& 120$; Variable income is 0 or $200(h)$; Round is round number within match; Other's $1^{\text {st }}$ transfer \& Other's $1^{\text {st }}$ transfer $\mid h$ is the $1^{\text {st }}$ transfer made by other within a match \& interaction with a dummy for the other being high at the time. 
Table 4 - Determinants of Transfers if Receiving $h$

\begin{tabular}{|l|c|c|c|}
\hline & $(1)$ & $(2)$ & $(3)$ \\
& Tobit, re & Tobit, re & Tobit, re \\
\hline Investment & -0.532 & -0.134 & -0.450 \\
& {$[0.095]^{* * *}$} & {$[0.072]^{*}$} & {$[0.096]^{* * *}$} \\
\hline Female & -8.789 & -34.164 & -5.927 \\
& {$[4.444]^{* *}$} & {$[4.246]^{* * *}$} & {$[5.960]$} \\
\hline Other's 1 $1^{\text {st }}$ transfer & 0.433 & 0.425 & 0.370 \\
& {$[0.103]^{* * *}$} & {$[0.115]^{* * *}$} & {$[0.115]^{* * *}$} \\
\hline Other's 1'transfer| $h$ & -0.169 & -0.244 & -0.190 \\
& {$[0.097]^{*}$} & {$[0.095]^{* *}$} & {$[0.096]^{* *}$} \\
\hline$\delta=.9$ & 20.948 & 16.074 & 7.010 \\
& {$[5.874]^{* * *}$} & {$[4.588]^{* * *}$} & {$[7.239]$} \\
\hline D70 & 25.333 & 22.544 & 20.240 \\
& {$[3.257]^{* * *}$} & {$[4.276]^{* * *}$} & {$[4.245]^{* * *}$} \\
\hline D120 & 24.991 & 26.137 & 25.302 \\
& {$[3.872]^{* * *}$} & {$[3.827]^{* * *}$} & {$[3.880]^{* * *}$} \\
\hline Round & -0.301 & -0.792 & -5.621 \\
& {$[0.268]$} & {$[0.467]^{*}$} & {$[1.478]^{* * *}$} \\
\hline Sex*other's $1^{\text {st transfer }}$ & & 0.132 & 0.139 \\
& & {$[0.083]$} & {$[0.082]^{*}$} \\
\hline Other's invest & & -0.151 & -0.156 \\
& & {$[0.070]^{* *}$} & {$[0.073]^{* *}$} \\
\hline Female other & & 3.867 & 2.696 \\
& & {$[2.846]$} & {$[2.766]$} \\
\hline Round*D70 & & 0.698 & 0.590 \\
& & {$[0.529]$} & {$[0.528]$} \\
\hline Round* $\delta=.9$ & & & 5.478 \\
& & & {$[1.462]^{* * *}$} \\
\hline Round*Female & & -0.926 \\
& & {$[7.318]$} & {$[9.529]^{*}$} \\
\hline Constant & & 30.924 \\
& & & {$[.743]^{* * *}$} \\
\hline
\end{tabular}

Observations: 1661. Number of unique identifiers for each individual: 94. Standard errors are in brackets. $*, * *$ and $* * *$ mean significant at $10 \%, 5 \%$ and $1 \%$, respectively, two-tailed tests. "re" stands for random effects. Investment $\&$ other's invest are the respective investments for the individual $\&$ the other person in the pair; D70 \& D120 are dummies for fixed income of $70 \& 120$; Variable income is 0 or $200(h)$; Round is round number within match; Other's $1^{\text {st }}$ transfer $\&$ Other's $1^{\text {st }}$ transfer $\mid h$ is the $1^{\text {st }}$ transfer made by other within a match \& interaction with a dummy for the other being high at the time. 
Table 5 - Determinants of Transfers if Not Receiving $h$

\begin{tabular}{|c|c|c|c|}
\hline & $\begin{array}{c}(1) \\
\text { Tobit, re }\end{array}$ & $\begin{array}{c}(2) \\
\text { Tobit, re }\end{array}$ & $\begin{array}{c}\text { (3) } \\
\text { Tobit, re }\end{array}$ \\
\hline Investment & $\begin{array}{c}0.144 \\
{[0.029]^{* * *}}\end{array}$ & $\begin{array}{c}0.106 \\
{[0.031]^{* * *}}\end{array}$ & $\begin{array}{c}-0.104 \\
{[0.037]^{* * *}}\end{array}$ \\
\hline Female & $\begin{array}{l}-0.387 \\
{[1.528]}\end{array}$ & $\begin{array}{c}-3.670 \\
{[1.829]^{* *}}\end{array}$ & $\begin{array}{c}0.703 \\
{[2.531]}\end{array}$ \\
\hline Other's $1^{\text {st }}$ transfer & $\begin{array}{c}0.143 \\
{[0.035]^{* * *}}\end{array}$ & $\begin{array}{c}0.113 \\
{[0.044]^{* * *}}\end{array}$ & $\begin{array}{c}0.142 \\
{[0.044]^{* * *}}\end{array}$ \\
\hline Other's $1^{\text {st }}$ transfer $\mid h$ & $\begin{array}{l}-0.075 \\
{[0.034]^{* *}}\end{array}$ & $\begin{array}{l}-0.085 \\
{[0.034]^{* *}}\end{array}$ & $\begin{array}{c}-0.122 \\
{[0.034]^{* * *}}\end{array}$ \\
\hline$\delta=.9$ & $\begin{array}{c}7.476 \\
{[2.810]^{* * *}}\end{array}$ & $\begin{array}{c}2.200 \\
{[3.031]}\end{array}$ & $\begin{array}{c}1.563 \\
{[2.708]}\end{array}$ \\
\hline D70 & $\begin{array}{c}12.350 \\
{[1.468]^{* * *}}\end{array}$ & $\begin{array}{c}8.914 \\
{[1.823]^{* * *}}\end{array}$ & $\begin{array}{c}9.107 \\
{[1.814]^{* * *}}\end{array}$ \\
\hline D120 & $\begin{array}{c}16.464 \\
{[1.714]^{* * *}}\end{array}$ & $\begin{array}{c}17.602 \\
{[1.706]^{* * *}}\end{array}$ & $\begin{array}{c}17.780 \\
{[1.709]^{* * *}}\end{array}$ \\
\hline Round & $\begin{array}{c}-0.292 \\
{[0.110]^{* * *}}\end{array}$ & $\begin{array}{c}-2.866 \\
{[0.694]^{* * *}}\end{array}$ & $\begin{array}{c}-2.810 \\
{[0.680]^{* * *}}\end{array}$ \\
\hline Sex*other's $1^{\text {st }}$ transfer & & $\begin{array}{c}0.082 \\
{[0.033]^{* *}}\end{array}$ & $\begin{array}{c}0.083 \\
{[0.033]^{* *}}\end{array}$ \\
\hline Other's invest & & $\begin{array}{c}0.055 \\
{[0.029]^{*}}\end{array}$ & $\begin{array}{c}0.059 \\
{[0.030]^{* *}}\end{array}$ \\
\hline Female other & & $\begin{array}{c}4.331 \\
{[1.182]^{* * *}}\end{array}$ & $\begin{array}{c}4.620 \\
{[1.186]^{* * *}}\end{array}$ \\
\hline Round*D70 & & $\begin{array}{c}0.606 \\
{[0.229]^{* * *}}\end{array}$ & $\begin{array}{c}0.632 \\
{[0.230]^{* * *}}\end{array}$ \\
\hline Round $* \delta=.9$ & & $\begin{array}{c}2.222 \\
{[0.703]^{* * *}}\end{array}$ & $\begin{array}{c}2.247 \\
{[0.675]^{* * *}}\end{array}$ \\
\hline Round*Female & & & $\begin{array}{c}-0.043 \\
{[0.211]}\end{array}$ \\
\hline Constant & $\begin{array}{c}-24.692 \\
{[3.516]^{* * *}}\end{array}$ & $\begin{array}{c}-19.690 \\
{[3.699]^{* * *}}\end{array}$ & $\begin{array}{c}-12.182 \\
{[3.744]^{* * *}}\end{array}$ \\
\hline
\end{tabular}

Observations: 1661. Number of unique identifiers for each individual: 94. Standard errors are in brackets. $*, * *$ and $* * *$ mean significant at $10 \%, 5 \%$ and $1 \%$, respectively, two-tailed tests. "re" stands for random effects. Investment \& other's invest are the respective investments for the individual \& the other person in the pair; D70 \& D120 are dummies for fixed income of $70 \& 120$; Variable income is 0 or 200 (h); Round is round number within match; Other's $1^{\text {st }}$ transfer \& Other's $1^{\text {st }}$ transfer $h$ is the $1^{\text {st }}$ transfer made by other within a match \& interaction with a dummy for the other being high at the time. 
Table 6 - Transfer and Beliefs

\begin{tabular}{|c|c|c|}
\hline & $\begin{array}{l}\text { (1) Tobit, re } \\
\text { Transfer }\end{array}$ & $\begin{array}{l}\text { (2) Tobit, re } \\
\text { Transfer if } h\end{array}$ \\
\hline Investment & $\begin{array}{c}-0.292 \\
{[0.157]^{*}}\end{array}$ & $\begin{array}{c}-0.679 \\
{[0.285]^{* *}}\end{array}$ \\
\hline Female & $\begin{array}{l}-6.033 \\
{[8.395]}\end{array}$ & $\begin{array}{c}-11.293 \\
{[15.567]}\end{array}$ \\
\hline Other's $1^{\text {st }}$ transfer & $\begin{array}{c}0.256 \\
{[0.079]^{* * *}}\end{array}$ & $\begin{array}{c}0.384 \\
{[0.100]^{* * *}}\end{array}$ \\
\hline Other's invest & $\begin{array}{l}-0.101 \\
{[0.102]}\end{array}$ & $\begin{array}{c}-0.275 \\
{[0.135]^{* *}}\end{array}$ \\
\hline Female other & $\begin{array}{c}-2.494 \\
{[4.797]}\end{array}$ & $\begin{array}{c}-0.682 \\
{[7.641]}\end{array}$ \\
\hline$\delta=.9$ & $\begin{array}{c}9.617 \\
{[8.724]}\end{array}$ & $\begin{array}{c}5.782 \\
{[16.296]}\end{array}$ \\
\hline D70 & $\begin{array}{c}22.109 \\
{[5.407]^{* * *}}\end{array}$ & $\begin{array}{c}30.447 \\
{[8.442]^{* * *}}\end{array}$ \\
\hline D120 & $\begin{array}{c}16.865 \\
{[5.604]^{* * *}}\end{array}$ & $\begin{array}{c}25.666 \\
{[9.168]^{* * *}}\end{array}$ \\
\hline Bdiff & $\begin{array}{c}8.374 \\
{[2.408]^{* * *}}\end{array}$ & $\begin{array}{c}14.172 \\
{[4.439]^{* * *}}\end{array}$ \\
\hline Round & $\begin{array}{c}-3.930 \\
{[2.082]^{*}}\end{array}$ & $\begin{array}{c}-6.235 \\
{[3.664]^{*}}\end{array}$ \\
\hline Round* Invest & $\begin{array}{c}0.007 \\
{[0.023]}\end{array}$ & $\begin{array}{c}0.031 \\
{[0.039]}\end{array}$ \\
\hline Round $* \delta=.9$ & $\begin{array}{c}1.973 \\
{[1.445]}\end{array}$ & $\begin{array}{c}2.856 \\
{[2.139]}\end{array}$ \\
\hline Round*Female & $\begin{array}{c}0.295 \\
{[1.227]}\end{array}$ & $\begin{array}{c}2.432 \\
{[1.973]}\end{array}$ \\
\hline Variable Income & $\begin{array}{c}0.189 \\
{[0.017]^{* * *}}\end{array}$ & \\
\hline Constant & $\begin{array}{c}-10.329 \\
{[13.831]}\end{array}$ & $\begin{array}{c}49.341 \\
{[21.965]^{* *}}\end{array}$ \\
\hline
\end{tabular}

Observations: 1661. Number of unique identifiers for each individual: 94 . Standard errors are in brackets. $*$, ** and $* * *$ mean significant at $10 \%, 5 \%$ and $1 \%$, respectively, two-tailed tests. "re" stands for random effects. Investment is the investment for the individual; D70 \& D120 are dummies for fixed income of 70 $\& 120$; Round is round number within match; Other's $1^{\text {st }}$ transfer is the $1^{\text {st }}$ transfer made by other within a match. Bdiff takes on the values $+1,0$, or -1 depending on whether one's expectations were exceeded, met, or not met. 